\title{
Pengaruh Citra Koperasi dan Kualitas Pelayanan terhadap Kepuasan Nasabah Koperasi Amertha Dana Lestari di Badung
}

\author{
Ni Made Wiwin Karuniati (1) \\ Ida Ayu Putu Widani Sugianingrat ${ }^{(2)}$ \\ Fakultas Ekonomi Bisnis dan PariwisataUniversitas Hindu Indonesia \\ Email : wiwinkaruniati@gmail.com
}

\begin{tabular}{|l|l|l|}
\hline Diterima: 21 Desember 2020 & Direvisi: 23 Desember 2020 & Disetujui: 26 Desember 20202 \\
\hline
\end{tabular}

\begin{abstract}
The purpose of this study was to determine the effect of cooperative image and service quality on customer satisfaction at the Amertha Dana Lestari Cooperative in Badung. This research was conducted at the Amertha Dana Lestari Cooperative in Badung. The number of samples was set at 90 respondents. The data analysis technique used multiple regression. Based on the results of the analysis it was found that partially the image of the cooperative has a positive and significant effect on savings customer satisfaction at the Amertha Dana Lestari Cooperative in Badung, service quality has a positive and partially significant effect on savings customer satisfaction at the Amertha Dana Lestari Cooperative in Badung, and the image of the cooperative and quality Simultaneous service has a positive and significant effect on customer satisfaction at the Amertha Dana Lestari Cooperative in Badung.
\end{abstract}

Keywords: cooperative image, service quality, customer satisfaction

\begin{abstract}
ABSTRAK
Tujuan penelitian ini adalah untuk mengetahui pengaruh citra koperasi dan kualitas pelayanan terhadap kepuasan nasabah tabungan pada Koperasi Amertha Dana Lestari di Badung. Penelitian ini dilakukan pada Koperasi Amertha Dana Lestari di Badung. Jumlah sampel ditetapkan sebanyak 90 responden. Teknik analisis data menggunakan regresi berganda. Berdasarkan hasil analisis ditemukan bahwa secara parsial citra koperasi berpengaruh positif dan signifikan terhadap kepuasan nasabah tabungan pada Koperasi Amertha Dana Lestari di Badung, kualitas pelayanan berpengaruh positif dan signifikan secara parsial terhadap kepuasan nasabah tabungan pada Koperasi Amertha Dana Lestari di Badung, serta Citra koperasi dan kualitas pelayanan secara simultan berpengaruh positif dan signifikan terhadap kepuasan nasabah tabungan pada Koperasi Amertha Dana Lestari di Badung.
\end{abstract}

Kata Kunci : citra koperasi, kualitas pelayanan, kepuasan nasabah 
Keberhasilan perusahaan dalam menjalankan pemasaran sangat ditentukan oleh kepuasan dari konsumen. Kepuasan konsumen senantiasa menjadi salah satu fokus dari setiap kegiatan usaha perusahaan. Kepuasan konsumen ini menjadikan evaluasi setelah dilakukannya pembelian suatu produk, dimana dapat sesuai atau mampu melebihi dari harapan konsumen. Menurut Lovelock, dkk. (2011:74) kepuasan adalah suatu sikap yang diputuskan berdasarkan pengalaman yangdidapatkan. Kotler, dkk. (2014:150) menyatakan bahwa kepuasan merupakan perasaan senang dan kecewa yang muncul setelah membandingkan kinerja (hasil) produk yang dipikirkan terhdap kinerja (atau hasil) yang diharapkan.

Kepuasan konsumen sangat dipengaruhi oleh citra. Citra mampu mempengaruhi persepsi konsumen dari produk atau jasa yang diatawarkan oleh perusahaan. Citra perusahaan dianggap sebagai persepsi masyarakat terhadap jati diri perusahan atau organisasi (Sutojo (2016:63)). Citra perusahaan yang bersumber dari pengalaman memberikan gambaran telah terjadi keterlibatan antara konsumen dengan perusahannya, upaya perusahaan sebagai sumber informasi yang lengkap, dimaksudkan informasi yang dapat menjawab kebutuhan dan keinginan objek sasaran (Zaynuri(2010:41)).

Kepuasan konsumen juga dapat dipengaruhi dan ditentukan oleh kualitas pelayanan. Harapan konsumen sebelum membeli adalah agar bisa mendapatkan pelayanan yang memuaskan. Maulidin, dkk (2013:67), mengemukakan bahwa kualitas pelayanan adalah seberapa jauh perbedaan antara kenyataan dan harapan pelanggan atau layanan yang mereka terima atau proleh. Kualitas pelayananadalah ukuran seberapa bagus tingkat layanan yang diberikan, mampu dan sesuai dengan ekspektasi pelanggan (Tjiptono (2012:57)). Berdasarkan hasil pengujian Nugroho dan Subagja (2018), yang menyatakan bahwa citra perusahaan dan kualitas pelayanan berpengaruh positif dan signifikan terhadap kepuasan konsumen. Sama halnya dengan hasil penelitian yang dilakukan oleh Mulyaningsih dan Suasana (2016), juga menunjukan bahwa citra perusahaan berpengaruh positif dan signifikan terhadap kepuasan nasabah.

Hasil pengujian yang dilakukan oleh Kusdayanti (2013), menunjukkan bahwa terdapat pengaruh positif dan signifikan antara citra terhadap kepuasan konsumen, sama halnya dengan penelitian yang pernah dilakukan oleh Nazria (2019), yang pada hasil penelitiannya menunjukkan bahwa citra koperasi berpengaruh positif dan signifikan terhadap kepuasan anggota di KPRI DWIJA Tonjong Kabupaten Brebes.Pada hasil pengujian yang dilakukan oleh Sinaga dan Kusmantoro (2015), menunjukkan ada pengaruh signifikan antara kualitas pelayanan dengan kepuasan. Penelitian yang sama dilakukan oleh Pontoh, dkk. (2014), yang menyatakan bahwa kualitas pelayanan secara simultan dan parsial memiliki pengaruh terhadap kepuasankonsumen. 
Koperasi adalah perkumpulan orang yang secara sukarela mempersatukan diri untuk berjuang meningkatkan kesejahteraan ekonomi mereka melalui pembentukan sebuah badan usaha yang dikelola secara demokratis (Rudianto (2010:3)). Salah satu koperasi yang ada di Bali adalah Koperasi Amertha Dana Lestari yang beralamat di Br. Bale Agung, Desa Cemagi, Kec. Mengwi, Kab.Badung. Didirikan sesuai dengan akte pendirian dengan nomor badan hukum : 37/BH/DISKOP/XI/2006. Hasil observasi awal pada Koperasi Amertha Dana Lestari di Badung, diketahui bahwa koperasi tersebut belum mampu memberikan kepuasan yang maksimal kepada nasabah tabungan, serta yang dirasa nasabah masih kurang menjaga kepercayaan dalam mengelola simpanannya. Hal ini dikatakan karena masih sering mendapatkan komplain dari nasabah tabungannya.

Tujuan penelitian ini adalah (1) untuk mengetahui pengaruh citra koperasi terhadap kepuasan nasabah tabungan pada Koperasi Amertha Dana Lestari diBadung, (2) untuk mengetahui pengaruh kualitas pelayanan terhadap kepuasan nasabah tabungan pada Koperasi Amertha Dana Lestari diBadung, dan (3) untuk mengetahui pengaruh citra koperasi dan kualitas pelayanan pada terhadap kepuasan nasabah tabungan pada Koperasi Amertha Dana Lestari di Badung.

\section{TELAAH LITERATUR DAN KAJIAN PUSTAKA}

\section{Kepuasan Pelanggan}

Kotler, et al. (2014:150) menyatakan Kepuasan Pelanggan adalah perasaan senang atau kecewa yang muncul setelah membandingkan kinerja (hasil) produk yang dipikirkan terhadap kinerja (atau hasil) yang diharapkan.Konsumen dapat mengalami salah satu dari tiga tingkat kepuasan umum yaitu kinerja di bawah harapan, konsumen akan merasa kecewa tetapi, jika kinerja sesuai dengan harapan pelanggan akan merasa sangat puas senang atau gembira (Kotler, et al. (2016:153)).

\section{Citra Koperasi}

Citra perusahaan (corporate image) merupakan representasi dari keseluruhan persepsi terhadap perusahaan dan dibentuk dari informasi dan pengalaman masa lalu terhadap perusahaan (Pradipta, 2012).Citra perusahaan yang melekat terhadap nasabah merupakan sebuah persepsi dari suatu perusahaan dalam benak nasabah yang terkait komitmen dan intensitas kepedulian dalam strategi berkomunikasi (Pradipta, 2012). Citra perusahaan yang bersumber dari pengalaman memberikan gambaran telah terjadi keterlibatan antara konsumen dengan perusahaannya, upaya perusahaan sebagai sumber informasi yang lengkap dimaksudkan sebagai informasi yang dapat menjawab kebutuhan dan keinginan objek sasaran (Zaynuri (2010:41)). 


\section{Kualitas Pelayanan}

Tjiptono (2012:157) mendefinisikan kualitas pelayanan adalah ukuran seberapa bagus tingkat layanan yang diberikan, mampu sesuai dengan ekspektasi pelanggan. Kualitas pelayanan menurut Wyckof dalam Lovelock yang dikutip oleh Tjiptono (2012:270) merupakan tingkat keunggulan (excellence) yang diharapkan dan pengendalian atas keunggulan tersebut untuk memenuhi keinginan pelanggan. Maulidin (2013:67) mengemukakan bahwa kualitas pelayanan adalah seberapa jauh perbedaan antara kenyataan dan harapan pelangganatau layanan yang mereka terima atau peroleh.

\section{Hipotesis}

$\mathrm{H}_{1}=$ Diduga Citra perusahaan berpengaruh positif dan signifikan terhadap kepuasannasabah.

$\mathrm{H}_{2}=$ Diduga Kualitas pelayanan berpengaruh positif dan signifikan terhadap kepuasan konsumen.

$\mathrm{H}_{3}=$ Diduga Citra Perusahaan dan Kualitas Pelayanan berpengaruh positif dan signifikan terhadap kepuasan nasabah.

\section{METODE PENELITIAN}

\section{Desain Penelitian}

Desain penelitian ini adalah penelitian deskriptif dengan pendekatan kuantitatif. Sujarweni (2018:87), menyatakan penelitian deskritif merupakan penelitian yang dilakukan untuk mengetahui nilai masing- masing variabel, baik suatu variabel atau lebih sifatnya independen untuk mendapatkan gambaran variabel - variabel tersebut. Nawawi (2005:63), menyatakan metode deskriptif dengan menggambarkan atau melukiskan keadaan objek penelitian pada saat sekarang berdasarkan fakta-fakta yang tampak atau sebagaimana adanya. 


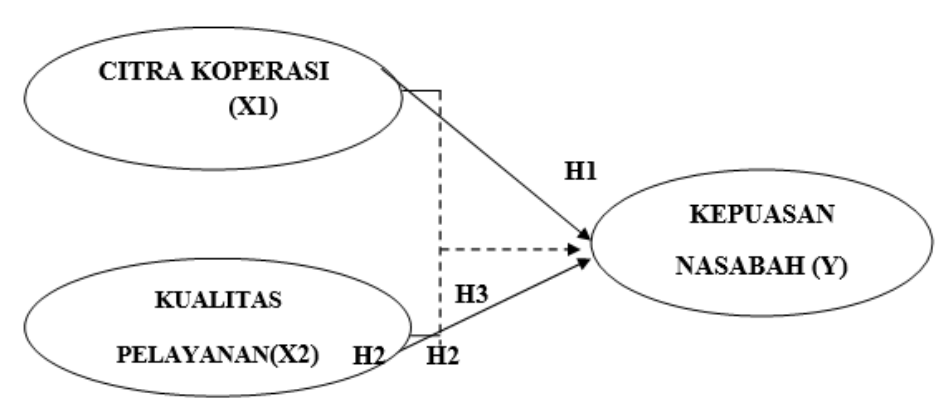

Gambar1. Kerangka Pemikiran

\section{Populasi dan Sampel}

Populasi dalam penelitian ini adalah seluruh nasabah penabung Koperasi Amertha Dana Lestari di Badung pada tahun 2018 yang sebanyak 916 orang penabung. Dengan menggunakan Rumus Slovin maka diperoleh sampel sebanyak 90 orang responden dengan metode penentuan sampel yang diguanakan adalah Sampling Insidental yang dimana teknik penentuan sampel berdasarkan kebetulan, yaitu siapa saja yang secara kebetulan/ insidental bertemu dengan peneliti dapat digunakan sebagai sampel, bila dipandang orang yang kebetulan itu cocok sebagai sumber data.

\section{Metode Pengumpulan Data}

Dalam penelitian ini, metode yang digunakan untuk mengumpulkan data antara lain observasi, wawancara, studi pustaka, dan kusioner. Skala pengukuran yang digunakan dalam kuisioner adalah Skala Likert dengan lima pilihan jawaban yang terdiri atas jawaban sangat setuju diberi skor5, jawaban setuju diberi skor4, jawaban cukup setuju diberi skor3, jawaban tidak setuju diberi skor2, dan jawaban sangat tidak setuju diberi skor1.

\section{Analisis Data}

Teknik analisis data yang digunakan dalam penelitian ini adalah analisis regresi linear berganda yang akan dikerjakan dengan menggunakan programSPSS (Statistica Program and Service Solution). Teknik analisis data ini bertujuan agar data yang diperoleh tersebut benar - benar handal, sehingga dapat dipertanggung jawabkankebenarannya.

\section{Metode Penelitian}


Bagian ini memuat rancangan penelitian atau desain penelitian, sasaran dan target penelitian (populasi dan sampel), teknik pengumpulan data, model/kerangka penelitian, dan teknik analisis.

\section{HASIL PENELITIAN DAN PEMBAHASAN}

\section{Uji Instrumen Penelitian}

Berdasarkan Tabel 1 menunjukkan bahwa seluruh instrumen penelitian variabel Citra Koperasi $\left(\mathrm{X}_{1}\right)$, Kualitas Pelayanan $\left(\mathrm{X}_{2}\right)$ dan Kepuasan Nasabah $(\mathrm{Y})$ seluruhnya adalah valid. Dikatakan valid karena semua instrumen penelitian memiliki koefisien korelasi pearson product moment $(\mathrm{r})>\mathrm{r}_{\text {tabel }}=0,3$ dan Tabel 1 juga menunjukkan bahwa instrumen penelitian variabel Citra Koperasi $\left(\mathrm{X}_{1}\right)$, Kualitas Pelayanan $\left(\mathrm{X}_{2}\right)$ danKepuasan Nasabah $(\mathrm{Y})$ seluruhnya adalah reliable. Dikatakan reliable karena semua instrumen penelitian memiliki koefisien cronbach's alpha $(\alpha)$ lebih dari 0,60.

Tabel 1.Hasil Uji Validitas dan Reliabilitas

\begin{tabular}{|c|c|c|c|c|c|}
\hline \multirow[b]{2}{*}{ Variabel } & \multirow{2}{*}{$\begin{array}{l}\text { Item } \\
\text { Pernyataan }\end{array}$} & \multicolumn{2}{|l|}{ Validitas } & \multicolumn{2}{|l|}{ Reliabilitas } \\
\hline & & $\begin{array}{l}\text { Koefisien } \\
\text { Korelasi }\end{array}$ & Keterangan & $\begin{array}{l}\text { Cronbach's } \\
\text { Alpha }\end{array}$ & Keterangan \\
\hline \multirow{4}{*}{$\begin{array}{l}\text { Citra } \\
\text { Koperasi } \\
\left(X_{1}\right)\end{array}$} & $\mathrm{X} 1.1$ & 0,796 & Valid & \multirow{4}{*}{0,861} & \multirow{4}{*}{ Reliabel } \\
\hline & $\mathrm{X} 1.2$ & 0,750 & Valid & & \\
\hline & $\mathrm{X} 1.3$ & 0,693 & Valid & & \\
\hline & $\mathrm{X} 1.4$ & 0,777 & Valid & & \\
\hline \multirow{9}{*}{$\begin{array}{l}\text { Kualitas } \\
\text { Pelayanan } \\
\left(\mathrm{X}_{2}\right)\end{array}$} & $\mathrm{X} 2.1$ & 0,716 & Valid & \multirow{9}{*}{0,868} & \multirow{9}{*}{ Reliabel } \\
\hline & X2.2 & 0,611 & Valid & & \\
\hline & $\mathrm{X} 2.3$. & 0,671 & Valid & & \\
\hline & $\mathrm{X} 2.4$ & 0,617 & Valid & & \\
\hline & $X 2.5$ & 0,665 & Valid & & \\
\hline & X2.6 & 0,643 & Valid & & \\
\hline & X2.7 & 0,697 & Valid & & \\
\hline & $\mathrm{X} 2.8$ & 0,779 & Valid & & \\
\hline & X2.9 & 0,767 & Valid & & \\
\hline \multirow{8}{*}{$\begin{array}{l}\text { Kepuasan } \\
\text { Nasabah } \\
\text { (Y) }\end{array}$} & Y1.1 & 0,645 & Valid & \multirow{8}{*}{0,834} & \multirow{8}{*}{ Reliabel } \\
\hline & $\mathrm{Y} 1.2$ & 0,745 & Valid & & \\
\hline & Y1.3 & 0,691 & Valid & & \\
\hline & Y1.4 & 0,692 & Valid & & \\
\hline & Y1.5 & 0,668 & Valid & & \\
\hline & Y1.6 & 0,713 & Valid & & \\
\hline & Y1.7 & 0,737 & Valid & & \\
\hline & Y1.8 & 0,562 & Valid & & \\
\hline
\end{tabular}

Sumber : data diolah, 2020

\section{Karakteristik Responden}


Dalam penelitian ini karakteristik responden digambarkan mengenai jenis kelamin, usia, pekerjaan, dan pendidikan. Adapun karakteristik yang terkumpul melalui pengumpulan kuesioner dapat dilihat pada Tabel 2.

Tabel 1.Karakteristik Responden

\begin{tabular}{lll}
\hline Kriteria & Jumlah (orang) & Persentase (\%) \\
Jenis Kelamin & 34 & 37,8 \\
Laki-laki & 56 & 62,2 \\
Perempuan & $\mathbf{9 0}$ & $\mathbf{1 0 0}$ \\
Total & & \\
Usia & 10 & 11,1 \\
17-25 tahun & 17 & 18,9 \\
26-30 tahun & 40 & 44,4 \\
31-40 tahun & 23 & 25,6 \\
40 tahun & $\mathbf{9 0}$ & $\mathbf{1 0 0}$ \\
Total & & \\
Pekerjaan & 6 & 6,7 \\
Ibu Rumah Tangga & 24 & 26,7 \\
Mahasiswa & 4 & 4,4 \\
Pelajar & 4 & 4,4 \\
Petani & 14 & 15,6 \\
PNS & 38 & 42,2 \\
Swasta & 90 & 100 \\
Total & & \\
Pendidikan & 22 & 24,4 \\
SMP & 40 & 44,4 \\
SMA/SMK & 18 & 20 \\
Diploma & 10 & 11,2 \\
Sarjana & $\mathbf{9 0}$ & $\mathbf{1 0 0}$ \\
Total & &
\end{tabular}

Sumber : data diolah, 2020

1. Berdasarkan jenis kelamin, dari 90 responden terdapat 34 orang $(37,8 \%)$ berjenis kelamin lakilaki dan 56 orang $(62,2 \%)$ berjenis kelamin perempuan. Keadaan ini menunjukkan bahwa mayoritas responden pada Koperasi Amertha Dana Lestari Badung berjenis kelamin perempuan.

2. Berdasarkan usia, diketahui bahwa dari 90 responden terdapat 10 orang $(11,1 \%)$ memiliki usia 17-25 tahun, 17 orang $(18,9 \%)$ memiliki usia 26-30tahun, 40 orang $(44,4 \%)$ memiliki usia 3140 tahundan 23 orang $(25,6 \%)$ memiliki usia > 40 tahun. Keadaan ini menunjukan bahwa mayoritas responden pada Koperasi Amertha Dana Lestari Badung berusia 31-40 tahun.

3. Karakteristik responden bedasarkan pekerjaan, dibagi menjadi enam kategori, diketahui bahwa dari 90 responden terdapat 6 orang $(6,7 \%)$ dengan pekerjaan sebagai ibu rumah tangga, 24 
orang $(26,7 \%)$ dengan pekerjaan sebagaiMahasiswa, 4 orang $(4,4 \%)$ dengan pekerjaan sebagai Pelajar, 4 orang $(4,4 \%)$ dengan pekerjaan sebagai Petani, 14 orang $(15,6 \%)$ dengan pekerjaan sebagai PNS dan 38 orang (42,2\%) dengan pekerjaan sebagai swasta. Keadaan ini menunjukkan bahwa mayoritas responden pada Koperasi Amertha Dana Lestari Badung bekerja sebagai swasta.

4. Berdasarkan Tabel 4.4 diketahui bahwa dari 90 responden terdapat 22 orang $(24,4 \%)$ dengan pendidikan sebagai SMP, 40 orang $(44,4 \%)$ dengan pendidikan sebagai SMA/SMK, 18 orang (20\%) dengan pendidikan sebagai diploma dan 10 orang $(11,2 \%)$ dengan pendidikan sebagai Sarjana. Keadaan ini menunjukkan bahwa mayoritas responden pada Koperasi Amertha Dana Lestari Badung pendidikan terakhirnya adalah SMA/SMK.

\section{Deskripsi Jawaban Responden}

Berdasarkan jawaban responden pada Tabel 3 diketahui persepsi responden mengenai citra koperasi pada Koperasi Amertha Dana Lestari adalah baik dengan nilai rata - rata secara keseluruhan sebesar 3,99. Hal ini berarti Koperasi Amertha Dana Lestari telah memberikan citra koperasi yang baik..Tabel 3. Distribusi Frekuensi Jawaban Responden Variabel Citra

\section{Koperasi}

\begin{tabular}{|c|c|c|c|c|c|c|c|}
\hline \multirow[t]{2}{*}{ Pernyataan } & \multicolumn{5}{|c|}{$\begin{array}{l}\text { Jawaban } \\
\text { Responden }\end{array}$} & \multirow{2}{*}{$\begin{array}{l}\text { Rata- } \\
\text { Rata } \\
\text { Skor }\end{array}$} & \multirow{2}{*}{$\begin{array}{l}\text { Kriteri } \\
\text { a }\end{array}$} \\
\hline & 1 & 2 & 3 & 4 & 5 & & \\
\hline $\begin{array}{l}\text { Koperasi Amertha Dana Lestari } \\
\text { berkesan dapat membantu nasabah } \\
\text { secara aman dalam menyimpan } \\
\text { tabungan nasabah }\end{array}$ & 0 & 0 & 23 & 50 & 17 & 3,93 & Baik \\
\hline $\begin{array}{l}\text { Koperasi Amertha Dana Lestari } \\
\text { memiliki pelayanan yang baik } \\
\text { dalam melayani nasabah tabungan. }\end{array}$ & 0 & 2 & 21 & 45 & 22 & 3,97 & Baik \\
\hline $\begin{array}{l}\text { Koperasi Amertha Dana Lestari } \\
\text { berlaku adil dan konsisten kepada } \\
\text { setiap nasabah }\end{array}$ & 0 & 0 & 16 & 50 & 24 & 4,09 & Baik \\
\hline $\begin{array}{l}\text { Pengurus dan karyawan koperasi } \\
\text { Amertha Dana Lestari sangat jujur } \\
\text { dan mampu bertanggung jawab } \\
\text { dalam mengelola tabungan nasabah. }\end{array}$ & 0 & 0 & 15 & 55 & 20 & 4,06 & Baik \\
\hline Rata-rata skor & & & & & & & Baik \\
\hline
\end{tabular}

Sumber : data diolah, 2020

Tabel 4.Distribusi Frekuensi Jawaban Responden Variabel Kualitas Pelayanan 


\begin{tabular}{|c|c|c|c|c|c|c|c|}
\hline \multirow[t]{2}{*}{ Pernyataan } & \multicolumn{5}{|c|}{$\begin{array}{l}\text { Jawaban } \\
\text { Responden }\end{array}$} & \multirow{2}{*}{$\begin{array}{l}\text { Rata- } \\
\text { rata } \\
\text { skor }\end{array}$} & \multirow[t]{2}{*}{ Kriteria } \\
\hline & 1 & 2 & 3 & 4 & 5 & & \\
\hline $\begin{array}{l}\text { Koperasi Amertha Dana Lestari } \\
\text { memiliki fasilitas yang lengkap. }\end{array}$ & 0 & 1 & 19 & 44 & 26 & 4,06 & Baik \\
\hline $\begin{array}{l}\text { Koperasi Amertha Dana Lestari } \\
\text { memiliki ruang tunggu yang nyaman }\end{array}$ & 0 & 0 & 23 & 42 & 25 & 4,02 & Baik \\
\hline $\begin{array}{l}\text { Koperasi Amertha Dana Lestari } \\
\text { cermat dalam memberikan informasi } \\
\text { pelayanan kepada nasabah tabungan. }\end{array}$ & 0 & 1 & 25 & 41 & 23 & 3,96 & Baik \\
\hline $\begin{array}{l}\text { Koperasi Amertha Dana Lestari } \\
\text { memiliki keahlian menggunakan } \\
\text { komputer dalam proses pelayanan. }\end{array}$ & 0 & 0 & 21 & 46 & 23 & 4,02 & Baik \\
\hline $\begin{array}{l}\text { Koperasi Amertha Dana Lestari } \\
\text { melayani nasabah tabungan secara } \\
\text { cepat. }\end{array}$ & 0 & 4 & 18 & 44 & 24 & 3,98 & Baik \\
\hline $\begin{array}{l}\text { Koperasi Amertha Dana Lestari } \\
\text { selalu merespon setiap keluhan } \\
\text { nasabah }\end{array}$ & 0 & 1 & 20 & 47 & 22 & 4,00 & Baik \\
\hline $\begin{array}{l}\text { Seluruh pengurus dan karyawan } \\
\text { Koperasi Amertha Dana Lestari } \\
\text { sudah memiliki kompetensi dan } \\
\text { professionalisme dalam melayani } \\
\text { nasabah tabungan. }\end{array}$ & 0 & 5 & 15 & 43 & 27 & 4,02 & Baik \\
\hline Skor rata-rata & & & & & & & Baik \\
\hline
\end{tabular}

Sumber : data diolah, 2020

Berdasarkan jawaban responden pada Tabel 4 diketahui persepsi responden mengenai kualitas pelayanan pada Koperasi Amertha Dana Lestari adalah baik dengan nilai rata - rata secara keseluruhan sebesar 3,97. Hal ini berarti Koperasi Amertha Dana Lestari telah memberikan kualitas pelayanan yang baik

Berdasarkan jawaban responden pada Tabel 5 diketahui persepsi responden mengenai kepuasan nasabah pada Koperasi Amertha Dana Lestaridiperoleh nilai rata - rata secara keseluruhan sebesar 4.14, dengan kriteria penilaian Tinggi. Hal ini berarti Koperasi Amertha Dana Lestari telah mampu memberikan kepuasan kepada nasabahnya.

Tabel 5. Distribusi Frekuensi Jawaban Responden Variabel Kepuasan Nasabah 


\begin{tabular}{|c|c|c|c|c|c|c|c|}
\hline \multirow[t]{2}{*}{ Pernyataan } & \multicolumn{5}{|c|}{$\begin{array}{l}\text { Jawaban } \\
\text { Responden }\end{array}$} & \multirow{2}{*}{$\begin{array}{l}\text { Rata- } \\
\text { Rata } \\
\text { Skor }\end{array}$} & \multirow[t]{2}{*}{ Kriteria } \\
\hline & 1 & 2 & 3 & 4 & 5 & & \\
\hline $\begin{array}{l}\text { Jasa tabungan yang diberikan pada } \\
\text { Koperasi Amertha Dana Lestari } \\
\text { mampu memuaskan } \\
\text { tabungan. }\end{array}$ & 0 & 0 & 17 & 44 & 29 & 4,13 & Tinggi \\
\hline $\begin{array}{l}\text { Pelayanan yang diberikan pada } \\
\text { Koperasi Amertha Dana } \\
\text { mampu Lestari } \\
\text { tabungan. }\end{array}$ & 0 & 0 & 10 & 52 & 28 & 4,20 & Tinggi \\
\hline $\begin{array}{l}\text { Bunga tabungan yang diterima oleh } \\
\text { nasabah tabungan Koperasi }\end{array}$ & 0 & 0 & 17 & 47 & 26 & 4,10 & Tinggi \\
\hline $\begin{array}{l}\text { Fasilitas penunjang pelayanan yang } \\
\text { didapatkan pada Koperasi Amertha } \\
\text { Dana Lestari sudah sesuai dengan } \\
\text { harapan nasabah tabungan. } \\
\text { Nasabah tabungan berminat untuk } \\
\text { berkunjung kembali ke Koperasi }\end{array}$ & 0 & 0 & 10 & 49 & 31 & 4,23 & $\begin{array}{l}\text { Sangat } \\
\text { Tinggi }\end{array}$ \\
\hline $\begin{array}{llcc}\text { Amertha Dana } & \text { Lestari } & \text { karena } \\
\text { pelayanan yang } & \text { diberikan } & \text { sangat } \\
\text { memuaskan. } & & \end{array}$ & 0 & 0 & 11 & 46 & 33 & 4,24 & $\begin{array}{l}\text { Sangat } \\
\text { Tinggi }\end{array}$ \\
\hline $\begin{array}{l}\text { Nasabah tabungan berminat untuk } \\
\text { berkunjung kembali ke Koperasi } \\
\text { Amertha Dana Lestari karena fasilitas } \\
\text { penunjang yang disediakan memadai. }\end{array}$ & 0 & 0 & 16 & 52 & 22 & 4,07 & Tinggi \\
\hline $\begin{array}{l}\text { Nasabah } \\
\text { merekomendasikan kepada teman } \\
\text { atau kerabat untuk ikut menggunakan } \\
\text { jasa tabungan yang ditawarkan di } \\
\text { Koperasi Amertha Dana Lestari } \\
\text { karena, pelayanan yang diberikan } \\
\text { memuaskan. }\end{array}$ & 0 & 0 & 21 & 48 & 21 & 4,00 & Tinggi \\
\hline $\begin{array}{l}\text { Nasabah tabungan menyarankan } \\
\text { kepada teman atau kerabat untuk } \\
\text { menyimpan tabungan pada Koperasi }\end{array}$ & & & & & & & \\
\hline $\begin{array}{l}\text { Amertha Dana Lestari, karena sudah } \\
\text { berkompeten tinggi r dan } \\
\text { profesionalisme dalam mengelola } \\
\text { tabungan nasabah. }\end{array}$ & 0 & 0 & 15 & 49 & 26 & 4,12 & Tinggi \\
\hline Rata-rata skor : & & & & & & 4,14 & Tinggi \\
\hline
\end{tabular}

Sumber : data diolah, 2020

\section{Uji Asumsi Klasik}


Berdasarkan Tabel 6 nilai Asymp. Sig. (2-tailed) =0,200. Nilai Sig. > 0,05 sehingga dapat disimpulkan seluruh data berdistribusi normal.

\section{Tabel 6. Hasil Uji Normalitas}

\begin{tabular}{lll}
\hline & & $\begin{array}{l}\text { Unstandardized } \\
\text { Residual }\end{array}$ \\
\hline $\mathrm{N}$ & & 90 \\
Normal Parameters & & 0 \\
& Mean & 2.17965521 \\
& Std. Deviation & 0.073 \\
Most Extreme Differences & Absolute & 0.054 \\
& Positive & -0.073 \\
Test Statistic & Negative & 0.073 \\
Asymp. Sig. (2-tailed) & & $.200^{\mathrm{c}, \mathrm{d}}$ \\
\hline
\end{tabular}

Sumber : data diolah, 2020

Berdasarkan Tabel 7 bahwa nilai tolerance masing-masing variabel lebih besar dari 0,10 dan nilai VIF lebih kecil dari 10, maka dapat disimpulkan tidak terjadi multikolinearitas atau tidak terjadi korelasi diantara variabel karakteristik individu dan karakteristik organisasi.

Tabel 7. Hasil Uji Multikolinearitas

\begin{tabular}{llll}
\hline \multirow{2}{*}{ Variabel } & \multicolumn{2}{l}{ Colinearity Statistic } & Keterangan \\
\cline { 2 - 4 } & Tolerance & VIF & \\
\hline Citra Koperasi $\left(\mathrm{X}_{1}\right)$ & 0,756 & 1,322 & Non Multikolinearitas \\
Kualitas Pelayanan $(\mathrm{X} 2)$ & 0,756 & 1,322 & Non Multikolinearitas \\
\hline
\end{tabular}

Sumber : data diolah, 2020

Berdasarkan Tabel 8 dijelaskan bahwa nilai signifikansi masing - masing variabel bebas dari Citra Koperasi $\left(\mathrm{X}_{1}\right)$ dan Kualitas Pelayanan $\left(\mathrm{X}_{2}\right)$ lebih dari alpha sebesar 0,05. Hal ini dapat disimpulkan bahwa tidak terjadi heteroskedastisitas pada model regresi.

\section{Tabel 8.Hasil Uji Heterpskedastisitas}




\begin{tabular}{|c|c|c|c|c|c|}
\hline \multirow[t]{2}{*}{ Model } & \multicolumn{2}{|c|}{ Unstandardized Coefficients } & $\begin{array}{l}\text { Standardized } \\
\text { Coefficients }\end{array}$ & \multirow[t]{2}{*}{$\mathrm{T}$} & \multirow[t]{2}{*}{ Sig } \\
\hline & $\mathrm{B}$ & Std. Error & Beta & & \\
\hline (Constant) & 2.548 & 1.246 & & 2.045 & .044 \\
\hline $\mathrm{X} 1$ & -.026 & .052 & -.063 & -.509 & .612 \\
\hline $\mathrm{X} 2$ & -.005 & .031 & -.018 & -.149 & .882 \\
\hline
\end{tabular}

Sumber : data diolah, 2020

\section{Analisis Regresi Linear Berganda}

Analisis ini digunakan untuk mengetahui besarnya pengaruh secara simultan antara Citra Koperasidan Kualitas Pelayanan terhadap Kepuasan Nasabah. Regresi linier berganda dinyatakan dalam bentuk persamaan garis regresi linier berganda yaitu $\hat{Y}=7,528+0,602 X_{1}+0,280 X_{2}$.

Tabel 9.Hasil Analisis Regresi linear Berganda

\begin{tabular}{|c|c|c|c|c|c|c|}
\hline \multicolumn{7}{|c|}{ Coefficients $^{\mathrm{a}}$} \\
\hline \multirow{2}{*}{\multicolumn{2}{|c|}{ Model }} & \multicolumn{2}{|c|}{$\begin{array}{l}\text { Unstandardardized } \\
\text { Coefficients }\end{array}$} & \multirow{2}{*}{$\begin{array}{l}\text { Standardized } \\
\text { Coefficients } \\
\text { Beta } \\
\end{array}$} & \multirow[t]{2}{*}{$\mathrm{T}$} & \multirow[t]{2}{*}{ Sig. } \\
\hline & & $\mathrm{B}$ & Std. Error & & & \\
\hline \multirow{3}{*}{1} & (Constant) & 7.528 & 2.084 & & 3.612 & .001 \\
\hline & $\mathrm{X} 1$ & .602 & .087 & .517 & 6.965 & .000 \\
\hline & $\mathrm{X} 2$ & .280 & .051 & .404 & 5.448 & .000 \\
\hline
\end{tabular}

Sumber : data diolah, 2020

Berdasarkan nilai $\alpha, b_{1}$,dan $b_{2}$ diperoleh persamaan garis regresi linier berganda antara Citra Koperasidan Kualitas Pelayanan terhadap Kepuasan Nasabah memberikan informasi bahwa: $\alpha=7,528$; nilai konstanta positif menunjukan pengaruh positif variabel Citra Koperasi $\left(\mathrm{X}_{1}\right)$ dan Kualitas Pelayanan $\left(\mathrm{X}_{2}\right)$. Artinya apabila tidak ada perhatian terhadap Citra Koperasi $\left(\mathrm{X}_{1}\right)$ dan Kualitas Pelayanan $\left(\mathrm{X}_{2}\right)$ atau nilainya adalah nol maka skor Kepuasan Nasabah adalah meningkatsebesar7,528.

$\mathrm{b}_{1}=0,602 ; \quad$ artinya apabila Kualitas Pelayanan $\left(\mathrm{X}_{2}\right)$ dianggap konstan maka meningkatnya skor Citra Koperasi $\left(\mathrm{X}_{1}\right)$ akan diikuti oleh meningkatnya skor Kepuasan Nasabah (Y) rata-rata sebesar0,602.

$\mathrm{b}_{2}=0,280, \quad$ artinya apabila skor Citra Koperasi $\left(\mathrm{X}_{1}\right)$ dianggap konstan maka menginkatnya skor Kualitas Pelayanan $\left(\mathrm{X}_{2}\right)$ diikuti oleh meningkatnya skor Kepuasan Nasabah (Y) rata-rata sebesar0,280.

\section{Analisis Koefisien Determinasi}


Berdasarkan Tabel 10 diketahui bahwa nilai $\mathrm{R}^{2}=63,7 \%$,artinya sebesar 63,7\% Kepuasan Nasabah (Y) dipengaruhi oleh variabel Citra Koperasi $\left(\mathrm{X}_{1}\right)$ dan Kualitas Pelayanan $\left(\mathrm{X}_{2}\right)$, sedangkan sisanya sebesar 36,3\% dipengaruhi oleh variabel lain yang tidak dianalisis dalam penelitian ini.Untuk membuktikan apakah Citra Koperasi $\left(\mathrm{X}_{1}\right)$ danKualitas Pelayanan $\left(\mathrm{X}_{2}\right)$ memang benar atau secara kebetulan mempengaruhi Kepuasan Nasabah (Y) maka akan diuji dengan menggunakan Uji F dan Ujit.

\section{Tabel 10.Hasil Analisis Koefisien Determinasi}

\begin{tabular}{llllll}
\hline Model & $\mathrm{R}$ & R Square & Adjusted R Square & $\begin{array}{l}\text { Std. Error of the } \\
\text { Estimate }\end{array}$ \\
\hline 1 & $.798^{\mathrm{a}}$ & 0.637 & 0.629 & 2.205 \\
\hline
\end{tabular}

Sumber : data diolah, 2020

\section{Uji Signifikansi Parsial (Uji-T)}

Uji statistik t pada dasarnya menunjukkan seberapa jauh pengaruh satu variabel penjelas / independen digunakan untuk menguji masing-masing hipotesis $\mathrm{H}_{1}$, dan $\mathrm{H}_{2}$ yaitu secara parsial variabel Citra Koperasi $\left(\mathrm{X}_{1}\right)$ dan Kualitas Pelayanan $\left(\mathrm{X}_{2}\right)$ terhadap Kepuasan Nasabah $(\mathrm{Y})$ adalah memang nyata terjadi (signifikan) atau hanya diperoleh secara kebetulan.

\section{Tabel 11.Hasil Uji-T}

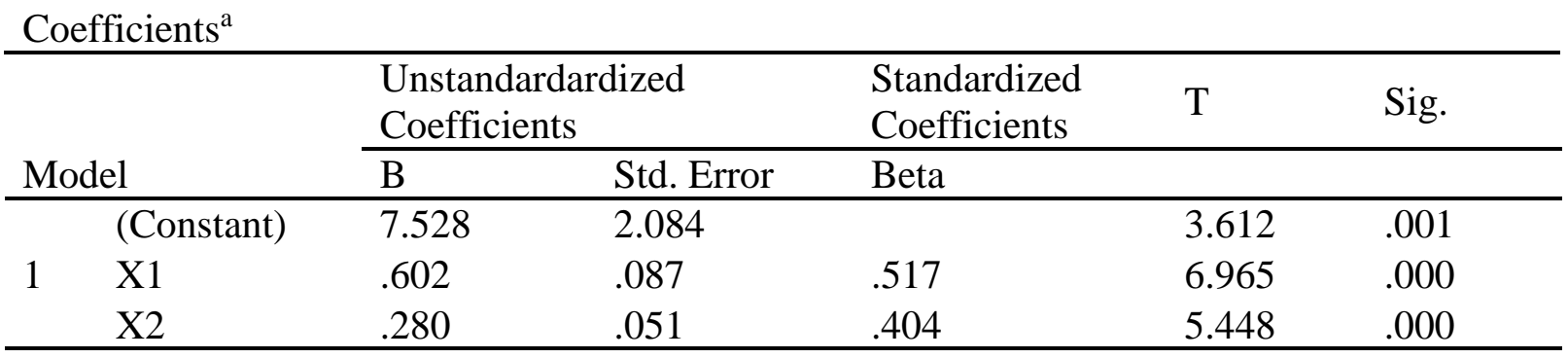

Sumber : data diolah, 2020

1. Pengaruh Citra Koperasi $\quad\left(\mathrm{X}_{1}\right)$ Terhadap KepuasanNasabah Tabungan Pada Koperasi Amertha Dana Lestari di Badung.

Berdasarkan hasil penelitian diketahui adanya pengaruh positifCitraKoperasi terhadapKepuasan Nasabah. Hal ini dibuktikan dengan hasil perhitungan yang diperoleh t-hitung1 adalah 6,965 lebih besar dibandingkan dari t-tabel 1,99 berada pada daerah penolakan $\mathrm{H}_{0}$. Dengan demikian $\mathrm{H} 0$ ditolak dan $\mathrm{H}_{\mathrm{a}}$ diterima. Ini berarti bahwa secara statistik untuk uji satu sisi pada taraf kepercayaan ( $\square$ ) $=5 \%$, secara parsial variable maka Citra Koperasi $\left(\mathrm{X}_{1}\right)$ berpengaruh positif dan signifikan terhadap Kepuasan Nasabah (Y) pada Koperasi AmerthaDana Lestaridi Badung dan tidak diperoleh secara 
kebetulan. Artinya jika terjadi peningkatan pada variabel Citra Koperasi (X1) maka akan meningkatkan Kepuasan Nasabah (Y). Dengan demikian hipotesis yang menyatakan bahwa Citra Koperasi (X1) berpengaruh positif dan signifikan secara parsial terhadap Kepuasan Nasabah tabungan pada Koperasi Amertha Dana Lestari di Badung telah teruji kebenarannya.

Hasil penelitian ini juga didukung dengan penelitian sebelumnya yang dilakukan oleh Mulyaningsih dengan Sudana (2016) dan Nugroho, dkk. (2018) yang menyatakan bahwa citra berpengaruh positif dan signifikan secara parsial terhadap kepuasan nasabah. Berbeda dengan hasil penelitian yang dilakukan oleh Pontoh, dkk. (2014), yang memperoleh hasil bahwa secara parsial citra tidak berpengaruh signifikan terhadap kepuasan nasabah.

2. Pengaruh Kualitas Pelayanan $\left(\mathrm{X}_{2}\right)$ Terhadap Kepuasan Nasabah Tabungan Pada Koperasi Amertha Dana Lestari diBadung.

Berdasarkan hasil penelitian diketahui adanya pengaruh positif dan signifikan terhadap kepuasan nasabah. Hal ini dibuktikan dari hasil perhitungan yang diperoleh diperoleh t-hitung2 adalah 5,448 lebih besar dari t-tabel 1,99 berada pada daerah penolakan $\mathrm{H}_{0}$ maka Kualitas Pelayanan $\left(\mathrm{X}_{2}\right)$ berpengaruh positif dan signifikan terhadap Kepuasan Nasabah(Y) pada Koperasi Amertha Dana Lestari di Badung dan tidak diperoleh secara kebetulan. Artinya jika terjadi peningkatan pada variabel kualitas pelayanan $\left(\mathrm{X}_{2}\right)$ maka akan meningkatkan kepuasan nasabah (Y). Dengan demikian hipotesis yang menyatakan bahwa Kualitas Pelayanan (X2) berpengaruh positif dan signifikan secara parsial terhadap KepuasanNasabahtabungan pada Koperasi Amertha Dana Lestari di Badung telah teruji kebenarannya.

Hasil Penelitian ini juga didukung dengan penelitian sebelumnya yang dilakukan oleh Kusdayanti (2016) dan Sinaga, dkk. (2015) yang menyatakan bahwa terdapat pengaruh positif dan signifikan kualitas pelayanan terhadap kepuasan nasabah.

\section{Uji Signifikansi Simultan (Uji-F)}

Uji ini digunakan untuk menguji signifikansi koefisien regresi $b_{1}, b_{2}$, sehingga diketahui apakah Citra Koperasi $\left(\mathrm{X}_{1}\right)$ dan Kualitas Pelayanan $\left(\mathrm{X}_{2}\right)$ secara simultan berpengaruh positif dan signifikan terhadap Kepuasan Nasabah (Y). 


\begin{tabular}{lllllll}
\hline Model & Sum of Square & df & Mean Square & F & Sig. \\
\hline \multirow{3}{*}{1} & Regression & 743.270 & 2 & 371.635 & 76.466 & $.000^{\mathrm{b}}$ \\
& Residual & 422.83 & 87 & 4.860 & & \\
& Total & 1166.1 & 89 & & & \\
\hline
\end{tabular}

Sumber : data diolah, 2020

Berdasarkan hasil penelitian diketahui adanya pengaruh secara simultan variabel citra koperasi dan kualitas pelyanan terhadap kepuasan nasabah. Hal ini dibuktikan dengan diperolehnya F-hitung $=76,466>\mathrm{F}$-tabel $=3,09$ berada pada daerah penolakan $\mathrm{H}_{0}$, maka $\mathrm{H}_{0}$ ditolak atau $\mathrm{H}_{\mathrm{a}}$ diterima. Berarti memang benar ada ada pengaruh positif dan signifikan secara simultan antara Citra Koperasi $\left(\mathrm{X}_{1}\right)$ dan Kualitas Pelayanan $\left(\mathrm{X}_{2}\right)$ terhadap Kepuasan Nasabah $(\mathrm{Y})$ di Koperasi Amertha Dana Lestari Badung dan tidak diperoleh secara kebetulan. Artinya jika terjadi peningkatan pada variable Citra Koperasi $\left(\mathrm{X}_{1}\right)$, Kualitas Pelayanan $\left(\mathrm{X}_{2}\right)$ maka akan meningkatkan kepuasan $\operatorname{nasabah}(\mathrm{Y})$.

Dengan demikian hipotesis yang menyatakan bahwa di Badung.Citra Koperasi $\left(\mathrm{X}_{1}\right)$, Kualitas Pelayanan $\left(\mathrm{X}_{2}\right)$ berpengaruh positif dan signifikan secara simultan terhadap Kepuasan Nasabah (Y) pada Koperasi Amertha Dana Lestari di Badung. Hasil penelitian ini juga mendukung penelitian sebelumnya yang dilakukan oleh Pontoh, dkk. (2014) dan Mulyaningsih, dkk. (2016) menyatakanbahwa Citra dan Kualitas Pelayanan secara simultan berpengaruh positif dan signifikan terhadap Kepuasan Nasabah.

\section{SIMPULAN}

Berdasarkan hasil analisis data dan pembahasan, maka dapat ditarik simpulan hasil penelitian sebagai berikut :

1. Citra Koperasi $\left(\mathrm{X}_{1}\right)$ berpengaruh positif dan signifikan secara parsial terhadap Kepuasan Nasabah di Koperasi Amertha Dana Lestari Badung. Hal tersebut dapat dibuktikan melalui hasil uji signifikan parsial (uji t-test) dimana diperoleh nilai $t_{\text {hitung }}$ dengan nilai $\mathrm{t}_{\text {-hitung }}=6,965>\mathrm{t}$-tabel $=1,99$ dan nilai $\mathrm{Sig} .=0,000<0,05$, berada pada daerah penolakan $\mathrm{H}_{0}$. Dengan demikian $\mathrm{H} 0$ ditolak dan $\mathrm{H}_{1}$ diterima. Hasil tersebut menunjukan semakin baik citra koperasi yang dirasakan oleh nasabah tabungan pada Koperasi Amertha Dana Lestari di Badung maka semakin tinggi pula tingkat kepuasan nasabah tabungan pada koperasitersebut.

2. Kualitas Pelayanan $\left(\mathrm{X}_{2}\right)$ berpengaruh positif dan signifikan seacara parsial terhadap Kepuasan Nasabah di Koperasi Amertha Dana Lestari Badung. Hal tersebut dibuktikan dengan nilai t-hitung $=5,448>\mathrm{t}_{\text {-tabel }}=1,99$ dan nilai Sig. $=0,000<0,05$, 
berada pada daerah penolakan $\mathrm{H}_{0}$, maka $\mathrm{H}_{0}$ ditolak dan $\mathrm{H}_{2}$ diterima. Hasil tersebut menunjukan semakin baik kualitas pelayanan yang dirasakan oleh nasabah tabungan pada Koperasi Amertha Dana Lestari di Badung maka semakin tinggi pula tingkat kepuasan nasabah tabungan pada koperasitersebut.

3. Citra Koperasi $\left(\mathrm{X}_{1}\right)$ dan Kualitas Pelayanan $\left(\mathrm{X}_{2}\right)$ berpengaruh secara simultan terhadap Kepuasan Nasabah di Koperasi Amertha Dana Lestari Badung. Hal tersebut dibuktikan dengan nilai $\mathrm{F}_{\text {-hitung }}=76.466>\mathrm{F}_{\text {-tabel }}=3,10$ dan nilai Sig. $=$ $0,000<0,05$, berada pada daerah penolakan $\mathrm{H}_{0}$, maka $\mathrm{H}_{0}$ ditolak atau $\mathrm{H}_{3}$ diterima. Hasil tersebut menunjukan semakin baik citra koperasi dan kualitas pelayanan yang dirasakan oleh nasabah tabungan pada Koperasi Amertha Dana Lestari di Badung maka semakin tinggi pula tingkat kepuasan nasabah tabungan pada koperasitersebut.

\section{Saran}

Berdasarkan pembahasan, kesimpulan di atas maka dapat diberikan saran sebagai berikut :

1. Melihat hasil bahwa citra koperasi berpengaruh positif dan signifikan terhadap kepuasan nasabah. Dapat disarankan bagi pihak pengurus dan pengelola Koperasi Amertha Dana Lestari di Badung diharapkan agar lebih memperhatikancitra koperasi di hadapan nasabah, dengan selalu meningkatkan citra koperasi yang baik, seperti menjaga persepsi nasabah koperasi agar selalu mendapatkan kesan yang baik di hadapan nasabah, selalu menjaga kepercayaan nasabah, melalui cara bertindak adil, konsisten, jujur adil dan mampu bertanggungjawab.

2. Bagi pihak pengurus dan pengelola Koperasi Amertha Dana Lestari di Badung agar lebih memperhatikan dan meningkatan kualitas pelayanan kepadaseluruhnasabahtabungan,sepertiselalubersikapramahdanmenjaga sopan santun dalam bertutur kata maupun berpenampilan, selalu cepat dan tanggap dalam melayani permasalahan nasabah tabungan.

3. Bagi pihak pengurus dan pengelola Koperasi Amertha Dana Lestari di Badung diharapkan agar lebih memperhatikan dan meningkatan citra koperasi dan kualitas pelayanan kepada seluruh nasabah tabungan. Kondisi ini terjadi karena nasabah lebih kritis dan lebih cerdas dalam memilih koperasi. 
4. Bagi peneliti selanjutnya, agar dapat menelitidan mengkaji lebih dalam faktorfaktor lain yang tidak diteliti dalam penelitian ini yang dapat mempengaruhikepuasan nasabah selain citra koperasi dan kualitas pelayanan. Sehingga nantinya dapat mengetahui tindakan apa yang harus dilakukan pihak Koperasi Amertha Dana Lestari di Badung dalam meningkatkan kepuasan nasabahtabungan.

\section{DAFTAR PUSTAKA}

Achmad Zaynuri. 2010. Diklat Bahan Ajar Elemen II. Universitas Mataram. Akbar, R.P.S dan Usman, H. 2013. Pengantar Statistika. Edisi Kedua.Yogyakarta.

Ali Hasan 2013, Marketing dan kasus - kasus pilihan. Yogyakarta CAPS (Center for Academic Publishing Service).

Astri Ocktora Sinaga, Kusumantoro. 2015. Pengaruh Kualitas Pelayanan, Kemampuan Manajerial Pengurus, Motivasi Anggota Dan Citra Koperasi Terhadap Kepuasan Anggota Koperasi Wahana Artha Nugraha. Jurnal Pendidikan Ekonomi Dinamika Pendidikan. Vol. X No. 1 Juni 2015, Hal. 1-15.

Anindya Yuli Astuti Nazria. 2019. Pengaruh Citra Koperasi, Pelayanan, Dan Motivasi Anggota Terhadap Kepuasan Anggota Koperasi Pegawai Republik Indonesia (KPRI) Dwija Tonjong Kabupaten Brebes. Jurnal Pendidikan dan Ekonomi, Volume 8, Nomor 1, tahun 2019: 44-50.

Budiarto Nugroho, Iwan Kurniawan Subagja. 2018. Pengaruh Kualitas Layanan Dan Citra Perusahaan Terhadap Kepuasan Nasabah PT. BANK Perkreditan Rakyat Gracia Mandiri Bekasi Timur. Jurnal ISSN:2338- 4794, Vol.6.No 1 Januari 2018:28-40.

Hadari, Nawawi. 2005. Metode Penelitian Bidang Sosial. Yogyakarta: Gadjah Mada Hardiansyah. 2011. Kualitas Pelayanan Publik. Yogyakarta:Gava Media John, Mullins and Orville, Walker, 2013: Marketing Management, 15 th edition. Kainidi. 2010,Pengaruh Customer Relationship, Citra Perusahaan, dan CustomerTrust Terhadap Loyalitas “COMPETITIVE'Majalah ilmiah, Vol 6 No.2.Desember 2010, ISSN : 02162539.

Kotler, Philip and Keller, Kevin Lane 2013. Manajemen Pemasaran, Jilid 2, Edisi 13, Erlangga : Jakarta.

Kotler, Philip \& Gerry Amstrong, 2014 : Principle Of Marketing, 15 th edition New Jersey :Pearson Pretice Hall.

Kotler dan Keller, 2014. Marketing Management Edisi 14, Global Edition.Pearson Prentice Hall.

Kotler, Philip and Kevin Lane Keller, 2016 : Marketing Management, 15 th Edition New Jersey:Pearson Pretice Hall, Inc.

Koperasi Amertha Dana Lestari.2018. Laporan Pertanggung Jawaban Tahunan Pengurus dan Pengawas Koperasi Amertha Dana Lestari, di Badung.

Lovelock, Christopher, Jochen Wirtz \& Jacky Mussry. 2011. Pemasaran jasa. Edisi 7. Erlangga : Jakarta

Luh Ayu Mulyaningsih, Gede Suasana.I.G.A.K. 2016. Pengaruh Kualitas Layanan Dan Citra Perusahaan Terhadap Kepuasan Nasabah. E-Jurnal Manajemen Unud, Vol.5,No. 1,2016: $1-30$. ISSN :23028912.

Maulidin, Munawir, 2013. Penerapan Model Pembelajaran Contextual Teaching and Learning dengan menggunakan strategi Problem Based Learning untuk meningkatkan Aktivitas dan belajar siswa kelas XI IS SMA Sinar Husni Medan Tahun Pembelajaran 2013/2014. Medan : Skripsi FE United. 
Michael B. Pontoh, Lotje Kawet, Willem A. Tumbuan. 2014. Kualitas Layanan, Citra Perusahaan Dan Kepercayaan Pengaruhnya Terhadap Kepuasan Nasabah BANK BRI Cabang Manado. Jurnal EMBA, Vol.2. No.3 September 2014: 285-297. ISSN2303-1174.

Mullin, John W dan Walker Jr. Olive C. 2013. Marketting Management: A. Strategic DecisionMaking Approach, 8 th Edition, McGraw-Hill International Edition.

Nazir, Moh. (2013). Metode Penelitian. Bogor: Ghalia Indonesia.

Niken Kusdayanti. 2016. Pengaruh Citra Koperasi Dan Kualitas Pelayanan Terhadap Kepuasan Anggota Koperasi Pegawai Republik Indonesia Setia Kecamatan Mojotengah Kabupaten

Wonosobo. Jurnal Pendidikan dan Ekonomi, Volume 5, Nomor 2 Tahun 2016: 124-131.

Pradipta, D. 2012. Pengaruh Citra Merek (Brand Image) Terhadap Loyalitas Konsumen Produk

Oli Pelumas PT Pertamina (PERSERO) Enduro Makasar, Sarjana strata 1. Universitas Hasanudin, Makasar (publish).

Rudianto, 2010. Akuntansi Koperasi edisi kedua. Jakarta : Erlangga.

Sugiyono.2008. Metode Penelitian Administrasi. Bandung Alfabeta. Sugiyono. 2010. Metode

Penelitian Bisnis. Bandung : Alfabeta.

Sugiyono.2013. Metode Penelitian Kuantitatif Kualitatif dan R\&D. Bandung: Alfabeta. CV

Sugiyono, 2014. Metode Penelitian Kuantitatif Kualitatif dan R\&D. Bandung: Alfabeta.

Sujarweni V. Wiratna, 2016. Metodologi Penelitian Bisnis dan ekonomi pendekatan kuantitatif, Yogyakarta : Pustaka Baru Press.

Sujarweni V. Wiratna,, 2018. Metodologi Penelitian Bisnis dan ekonomi pendekatan kuantitatif, Yogyakarta : Pustaka Baru

Siswanto Sutojo. 2016. Metode Penelitian : Kuantitatif, Kualitatif dan R\&D. Bandung : Alfabeta Sugiyono, 2017. Statistika Untuk Penelitian. Bandung : Alfabeta.

Tjiptono, Fandy\&Gregorius Chandra, 2011, Service Quality \& Satification, Edisi 3, Andi :Yogyakarta.

Tjiptono, Fandy, 2012, Pemasaran Jasa, Andy Offset : Yogyakarta. 